\title{
Slowing of electrical activity in ventricular fibrillation is not associated with increased defibrillation energies in the isolated rabbit heart
}

\author{
Jane C. Caldwell, Francis L. Burton, Stuart M. Cobbe and Godfrey L. Smith*
}

Institute of Cardiovascular and Medical Sciences, University of Glasgow, Glasgow, UK

Edited by:

Tobias Opthof, Academic Medical

Center, Netherlands

Reviewed by:

Haruo Honjo, Research Institute of

Environmental Medicine, Nagoya

University, Japan

Antoni Cg Van Ginneken, Academic

Medical Centre, Netherlands

*Correspondence:

Godfrey L. Smith, University of

Glasgow, West Medical Building,

Glasgow G128QQ, UK.

e-mail: godfrey.smith@glasgow.ac.uk
Prolonged out-of-hospital ventricular fibrillation (VF) arrests are associated with reduced ECG dominant frequency (DF) and diminished defibrillation success. Partial reversal of ischemia increases ECG DF and improves defibrillation outcome. We have investigated the metabolic components of ischemia responsible for the decline in ECG DF and defibrillation success. Isolated Langendorff-perfused rabbit hearts were loaded with the voltage-sensitive dye $\mathrm{RH} 237$. Using a photodiode array, epicardial membrane potentials were recorded at 252 sites $(15 \mathrm{~mm} \times 15 \mathrm{~mm})$ on the anterior surface of the left and right ventricles. Simultaneously, a global ECG was recorded. VF was induced by burst pacing, and after 60 s, perfusion was either reduced to $6 \mathrm{ml} / \mathrm{min}$ or the perfusate composition changed to impose hypoxia $\left(95 \% \mathrm{~N}_{2} / 5 \% \mathrm{CO}_{2}\right), \mathrm{pH}$ $6.7\left(80 \% \mathrm{O}_{2} / 20 \% \mathrm{CO}_{2}\right)$, or hyperkalemia $(8 \mathrm{mM})$. Using fast Fourier transform, power spectra were created from the optical signals and the global ECG. The optical power spectra were summated to give a global power spectrum (pseudoECG). At $600 \mathrm{~s}$ the minimum defibrillation voltage (MDV) was determined by step-up protocol. During VF, the ECG and pseudoECG DF were reduced by low-flow ischemia $(9.0 \pm 1.0 \mathrm{~Hz}, p<0.01, n=5)$ and raised $\left[\mathrm{K}^{+}\right]_{0}(12.2 \pm 1.3 \mathrm{~Hz}$, $p<0.05, n=7)$ compared to control $(19.2 \pm 1.5 \mathrm{~Hz}, n=20)$, but were unaffected by acidic $\mathrm{pH}_{\text {。 }}$ $(16.7 \pm 1.1 \mathrm{~Hz}, n=11)$ and hypoxia $(14.0 \pm 1.2 \mathrm{~Hz}, n=10)$. In contrast, the MDV was raised by acidic $\mathrm{pH}(156.1 \pm 26.4 \mathrm{~V}, p<0.001)$ and hypoxia $(154.1 \pm 22.1 \mathrm{~V}, p<0.01)$ compared to control $(65.6 \pm 2.3 \mathrm{~V})$, but comparable changes were not observed in low-flow ischemia $(61.0 \pm 0.5 \mathrm{~V})$ or raised $\left[\mathrm{K}^{+}\right]_{0}(56 \pm 3 \mathrm{~V})$. In summary, different metabolites are responsible for the reduction in DF and the increase in defibrillation energy during ischemic VF.

Keywords: optical mapping, ischemia, ventricular fibrillation, defibrillation

\section{INTRODUCTION}

Ventricular fibrillation (VF) is the major cause of sudden death, with an estimated Europe-wide annual mortality of 123,000 (Atwood et al., 2005). In VF, the dyssynchronous electrical activity within the ventricles results in loss of cardiac output and death, unless corrective measures, including electrical defibrillation, are undertaken (Rubart and Zipes, 2005). It is well established that prolonged out-of-hospital VF arrests are associated with slowing of the heart's electrical activity, as reflected by lowering of the frequency of oscillation in the surface ECG (Stewart et al., 1992). This slower electrical activity is associated with diminished defibrillation success (Stewart et al., 1992). More recently, studies have shown that partial re-establishment of perfusion by CPR increased the ECG dominant frequency (DF; Eftestol et al., 2004) and improved defibrillation success (Wik et al., 2003). This suggests that the energy required to defibrillate successfully (defibrillation threshold, DFT) is increased by ischemia, and reduced by partial restoration of coronary perfusion.

In contrast, experimental assessments of DFT failed to show any increase in DFT during global ischemia (Behrens et al., 1997; Barton et al., 2000) but DFTs were increased during localized regional ischemia (Ouyang et al., 1981; Qin et al., 2002; Anastasiou-Nana et al., 2005). Similarly computer simulations predict a reduction of
DFT in global ischemia (Rodriguez et al., 2004) and an increase in cardiac vulnerability to recurrent VF after defibrillation in regional ischemia (Rodriguez et al., 2006).

One possible explanation for this apparent paradox is that the principal metabolic components of ischemia, namely hypoxia, acidosis, and hyperkalemia, individually affect the DF and DFT in different ways. Altering the proportions of these individual components could therefore affect the apparent relationship between DF and DFT. The aim of this study was to determine the individual effects of hypoxia, acidosis, and hyperkalemia on the frequency of the electrical oscillations during VF and the required defibrillation energy.

\section{MATERIALS AND METHODS LANGENDORFF PERFUSION}

Adult male New Zealand White rabbits (weight 3-3.5 kg) were sacrificed by intravenous injection of $0.5 \mathrm{ml} / \mathrm{kg}$ Euthatal (sodium pentobarbitone $200 \mathrm{mg} / \mathrm{kg}$, Rhône Mérieux) with $500 \mathrm{IU}$ of heparin. Hearts were rapidly excised, and Langendorff-perfused with Tyrode's solution at $37^{\circ} \mathrm{C}$ at constant rate of $40 \mathrm{ml} / \mathrm{min}$ [Tyrode's composition (mM): Na 134.5, Mg 1.0, K 5.0, Ca 1.9, Cl 101.8, $\mathrm{SO}_{4} 1.0, \mathrm{H}_{2} \mathrm{PO}_{4} 0.7, \mathrm{HCO}_{3} 20$, acetate 20 , glucose 50 , and $\left.\mathrm{pH} 7.4\left(95 \% \mathrm{O}_{2} / 5 \% \mathrm{O}_{2}\right)\right]$. 


\section{OPTICAL MAPPING}

Hearts were placed in a custom-made Plexiglas chamber (Figure 1A) that allowed control of bathing solution composition and temperature via separate bath perfusion, recording of global ECG from fixed electrodes (Figure 1B) and defibrillation through two steel paddles that cradled the heart $(n=53)$. Optical mapping of the anterior epicardial surfaces of the left and right ventricles was performed as previously published (Kettlewell et al., 2004). Briefly, hearts were loaded with a bolus of $100 \mu \mathrm{l}$ of $1 \mathrm{mg} / \mathrm{ml} \mathrm{RH} 237$ (Molecular Probes), dissolved in DMSO. Light at 535 $\pm 25 \mathrm{~nm}$ (interference filter, Comar Instruments Ltd, UK) from four $75 \mathrm{~W}$ tungsten-halogen lamps illuminated the heart's anterior surface. Fluorescent light was passed through a 695-nm long-pass filter, and focused onto a $16 \times 16$ photodiode array (C4675-102, Hamamatsu Photonics UK Ltd). Each diode detected light from $0.8 \mathrm{~mm} \times 0.8 \mathrm{~mm}$ area of epicardium; the full array recorded from $15 \mathrm{~mm} \times 15 \mathrm{~mm}$ area. Typical optical signals from a single diode are shown in Figure 1C. Digitalized data $(1 \mathrm{kHz})$ were stored to disk, and analyzed using software written in Delphi (Borland Software Corp., CA, USA).
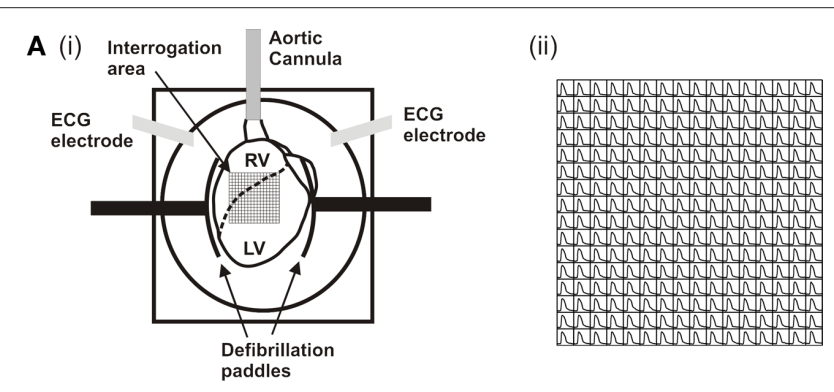

B

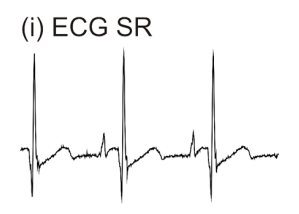

C (i) Optical SR

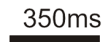

(ii) ECG VF
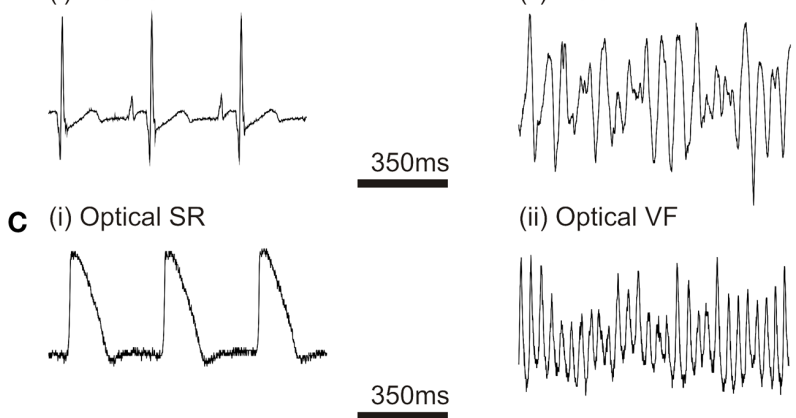

(ii) Optical VF

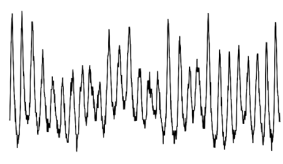

D

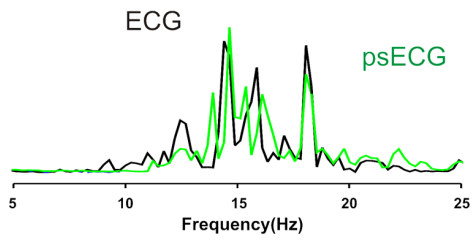

FIGURE 1 | (Ai) Langendorff-perfused rabbit heart in optical mapping chamber. The superimposed grid represents the area of the myocardium $(16 \times 16$ pixels) visualized by the photodiode array. (Aii) Optically recorded action potentials (pacing cycle length $300 \mathrm{~ms}$ ). ECG recording during (Bi) sinus rhythm and (Bii) ventricular fibrillation (VF). Optical pixel recordings in (Ci) sinus rhythm, (Cii) VF. (D) Superimposed power spectra of ECG (Bii) and the summary psECG of all 256 pixels in VF.
During optical recordings hearts were immobilized by transient compression so that no excitation-contraction uncoupling agents were employed for the $4 \mathrm{~s}$ epoch of data recording.

\section{VF PROTOCOL AND ANALYSIS}

Ventricular fibrillation was induced by burst pacing $(50 \mathrm{~Hz}$ stimulation for $8 \mathrm{~s}$ ) via platinum hook electrodes placed in the RV. All hearts were perfused with normal Tyrode's solution at $40 \mathrm{ml} /$ min for the first $60 \mathrm{~s}$ of VF. A single protocol was carried out in each heart. ECG and optical recordings were taken every $60 \mathrm{~s}$, each recording $4 \mathrm{~s}$ worth of VF. In control protocols, $40 \mathrm{ml} / \mathrm{min}$ perfusion with standard Tyrode's solution was maintained. In experimental protocols, either the perfusion rate (low-flow ischemia $=6 \mathrm{ml} / \mathrm{min}$ ), or solution composition was altered at $60 \mathrm{~s}$. The heart chamber was filled in two ways: (i) indirectly from the coronary sinus effluent and (ii) directly from a second bath perfuser whose composition was changed inline with the Langendorff perfusate. VF continued in all protocols until $600 \mathrm{~s}$. On completion of the recording at 600 s, ECG electrodes were isolated and hearts were defibrillated using a Ventak ECD 2815 (CPI, St Paul, MN, USA). This defibrillator contains a $140-\mu \mathrm{F}$ capacitor with $80 \%$ fixed tilt, first phase $60 \%$ of total duration and automatic adjustment of waveform duration to resistance load (automatic impedance compensation). As heart resistance was constant at $\sim 48 \Omega$, the biphasic waveform duration was also constant at $\sim 14 \mathrm{~ms}$. Shocks were delivered with fixed polarity orientation via custom-made stainless steel paddles (Figure 1A). Shocks of discrete strength settings were delivered by a step-up protocol. The time between shock applications was about $5 \mathrm{~s}$, so the maximum delay between application of first shock and eventual defibrillation was $40 \mathrm{~s}$. Minimum defibrillation voltage (MDV) was determined as the shock strength that successfully defibrillated VF into sinus rhythm (Barton et al., 2000). As shown in Table 1, there was slight variation in the actual shock delivered at each strength setting. The actual shock strength rather than the setting was recorded. The impedance compensation prohibited the use of additional resistors in series in attempts to apply lower strength shocks as the additional loading resulted in waveform prolongation. Increased waveform duration for same energy delivery has been linked to less efficient defibrillation (Natale et al., 1996; Ideker et al., 2006).

Fast Fourier transform (FFT) of the ECG and optical signals during VF was performed on $4 \mathrm{~s}$ data recordings. As with previous clinical studies (Strohmenger et al., 1997), the DF of these signals

Table 1 | Energy settings of the Ventak ECD 2815 with the corresponding voltage, energy, and waveform delivered.

\begin{tabular}{llll}
\hline $\begin{array}{l}\text { Energy } \\
\text { setting }(\mathbf{J})\end{array}$ & $\begin{array}{l}\text { Mean } \\
\text { voltage } \pm \text { SD (V) }\end{array}$ & $\begin{array}{l}\text { Mean } \\
\text { energy } \pm \text { SD (J) }\end{array}$ & Waveform \\
\hline 0.3 & $61 \pm 1.8$ & $0.298 \pm 0.006$ & Biphasic \\
0.5 & $79 \pm 2.9$ & $0.477 \pm 0.008$ & Biphasic \\
0.8 & $99 \pm 3.9$ & $0.759 \pm 0.013$ & Biphasic \\
1.0 & $111 \pm 3.8$ & $0.960 \pm 0.015$ & Biphasic \\
2.0 & $155 \pm 4.7$ & $1.895 \pm 0.039$ & Biphasic \\
3.0 & $189 \pm 7.9$ & $2.836 \pm 0.055$ & Biphasic \\
4.0 & $217 \pm 6.9$ & $3.778 \pm 0.061$ & Biphasic \\
5.0 & $244 \pm 7$. & $4.705 \pm 0.092$ & Biphasic
\end{tabular}


was taken as the frequency with the greatest power between 3 and $50 \mathrm{~Hz}$. The peak (dominant) frequency (DF) was identified from power spectra of ECG (Carlisle et al., 1990; Strohmenger et al., 1997) and optical signals (Chen et al., 2000; Samie et al., 2001; Choi et al., 2006). Summing the power spectra from all 256 pixels gave a global or pseudoECG (psECG) power spectrum (Figure 1D). The progressive changes in psECG DF were similar to ECG DF, therefore only the psECG DF data are presented (Figure 2).

Heterogeneity of repolarization and refractoriness is thought to play a role in defibrillation outcome (Ujhelyi et al., 1999). During VF, it is assumed that a heart cell is activated as soon as it is able and the interval between activations (i.e., the VF interval, VFI) reflects the refractory period of the underlying tissue (Opthof et al., 1991, 1993). Epicardial refractoriness during VF can be assessed by measurement of the VFI over the surface sites. Therefore the dispersion of refractoriness can be measured by quantifying the coefficient of variance (CoV) of VFIs. In this study, the CoV was measured as the standard deviation of the mean DF across the epicardial surface relative to the mean $\mathrm{DF}(\mathrm{SD} \times 100 /$ mean $)$ and was used to represent the dispersion of refractoriness (Opthof et al., 1991, 1993; Burton and Cobbe, 1998; Burton et al., 2000). As well as measuring the CoV, the fractional change in the $\mathrm{CoV}$ at defibrillation was compared to that immediately on VF induction to quantify the relative change in $\mathrm{CoV}$ for each condition.

\section{COMPONENTS OF ISCHEMIA}

To study the contribution of individual ischemic components to the changes in DF, CoV, and MDV, standard Tyrode's solution was altered to impose each component according to previous studies (Kleber, 1983; Jennings et al., 1990; Bethell et al., 1998). Acidic $\mathrm{pH}_{\mathrm{o}}=6.7$ was produced by bubbling with $20 \% \mathrm{CO}_{2} / 80 \% \mathrm{O}_{2}$ (Bethell et al., 1998); hypoxia was produced by bubbling with 5\% $\mathrm{CO}_{2} / 95 \% \mathrm{~N}_{2}$ mixture (Jennings et al., 1990); hyperkalemia was produced using $8 \mathrm{mM}$ or $10 \mathrm{mM}\left[\mathrm{K}^{+}\right]_{\mathrm{o}}$ (Kleber, 1983). Perfusion with experimental solutions cause no visible change in isolated heart dimensions suggesting no major shifts in intracellular fluids during the various interventions.

\section{STATISTICAL ANALYSIS}

Data are expressed as mean \pm SEM. Significance testing with repeated paired ANOVA was performed using Instat3 (GraphPad Software Inc., USA) after all parameters were tested for normality. Comparisons at defibrillation were made between psECG DFs, the MDVs, and the fractional change of the CoV compared to baseline. All graphs including scattergrams were plotted using Origin (OriginLab Corp., MA, USA). The linear-fit algorithms within this software package used to assess the correlation coefficient.

\section{RESULTS}

\section{VARIATION OF psECG DF}

Figure 2A shows that at defibrillation, the psECG DF in low-flow ischemia of $9.0 \pm 1.0 \mathrm{~Hz}(n=5)$ was significantly lower than psECG DF in control of $19.2 \pm 1.5 \mathrm{~Hz}\left({ }^{* *} p<0.01\right.$, Figure 2A). Similarly, psECG DF in $8 \mathrm{mM}\left[\mathrm{K}^{+}\right]_{0}$ of $12.2 \pm 1.3 \mathrm{~Hz}(n=7)$ was significantly lower than control $\left(n=20 ;{ }^{*} p<0.05\right.$, Figure $\left.2 \mathrm{~A}\right)$. During perfusion with $10 \mathrm{mM}\left[\mathrm{K}^{+}\right]_{\mathrm{o}}$, VF converted spontaneously to a regular ventricular escape rhythm $(\sim 3 \mathrm{~Hz})$.
In contrast, psECG DF of $16.7 \pm 1.1 \mathrm{~Hz}$ in $\mathrm{pH} 6.7(n=11)$, and $14.0 \pm 1.2 \mathrm{~Hz}$ in hypoxia $(n=10)$ were not significantly different from control (Figure 2A).

\section{MINIMUM DEFIBRILLATION VOLTAGE}

As shown in Figure 2B, the mean MDV required to defibrillate VF in low-flow ischemia of $61.0 \pm 0.5 \mathrm{~V}$ was not significantly different from the $65.6 \pm 2.3 \mathrm{~V}$ in control. Although there was a tendency for MDV to be reduced to $59.0 \pm 0.3 \mathrm{~V}$ in $8 \mathrm{mM}\left[\mathrm{K}^{+}\right]_{\mathrm{o}}$, this was not significantly different from control. $10 \mathrm{mM}\left[\mathrm{K}^{+}\right]_{0}$ solution spontaneously converted VF to a regular ventricular escape rhythm before $600 \mathrm{~s}$. All defibrillations in this group were achieved using the minimum setting on the defibrillator. The variation in recorded voltages reflects the variation in the resistance of the isolated heart preparations.

Figure 2B also shows that significantly stronger shocks were required to defibrillate VF during $\mathrm{pH} 6.7$ and hypoxia compared to control. In pH 6.7 the MDV was $156.1 \pm 26.4 \mathrm{~V}\left({ }^{* *} p<0.01\right)$, and in hypoxia the MDV was $154.1 \pm 22.1 \mathrm{~V}\left({ }^{* *} p<0.01\right)$.

\section{DF AND MDV}

The mean MDV and psECG DF data did not display any correlation. Therefore individual MDVs were plotted against the respective psECG DF as a scattergram (Figure 2C). In acidic $\mathrm{pH}_{\mathrm{o}}$ and hypoxia there was no correlation between MDV to increase as DF increased. Nor was there any correlation in the control, low-flow ischemia or raised $\left[\mathrm{K}^{+}\right]_{0}$.

\section{COEFFICIENT OF VARIANCE}

Immediately post VF induction, the $\mathrm{CoV}$ was not different between protocols (data not shown). As VF progressed, the CoV tended to increase with time in all protocols apart from the $\mathrm{pH} 6.7$ group, where it remained relatively constant (Figure 3A). However, at defibrillation there were no significant differences in $\mathrm{CoV}$ as assessed by absolute values and fractional changes (Figure 3B).

\section{DISCUSSION}

This study demonstrated that in the isolated Langendorff-perfused rabbit heart, conditions that slow the electrical activity in VF do not increase the required defibrillation energy. The electrical activity in VF was significantly slowed by low-flow ischemia and raised $\left[\mathrm{K}^{+}\right]_{0}$, whilst MDV was not increased above the minimum values that could be delivered by the defibrillator. In contrast, MDV was significantly increased by perfusion with acidic solutions ( $\mathrm{pH}$ 6.7) and hypoxia. Neither of these condition had significant effects on the VF frequency. These results establish for the first time that DF and DFT may not be mechanistically linked. The limited area of epicardium imaged in these experiments was considered to sample the major axis of heterogeneity in VF frequency in the rabbit ventricle. In support of this, previous studies (Wu et al., 2006) found that the greatest differential in the DF of VF was during low-flow ischemia, with a lower DF value in LV epicardial relative to RV. No significant differences between LV and RV endocardium and RV epicardium were observed.

\section{IN LOW-FLOW ISCHEMIA}

Successful defibrillation requires a shock to depolarize sufficient myocardium homogeneously to stop fibrillation wavefronts without launching new activation waves. Defibrillation fails when the shock that terminates fibrillation also reinitiates fibrillation. Several 

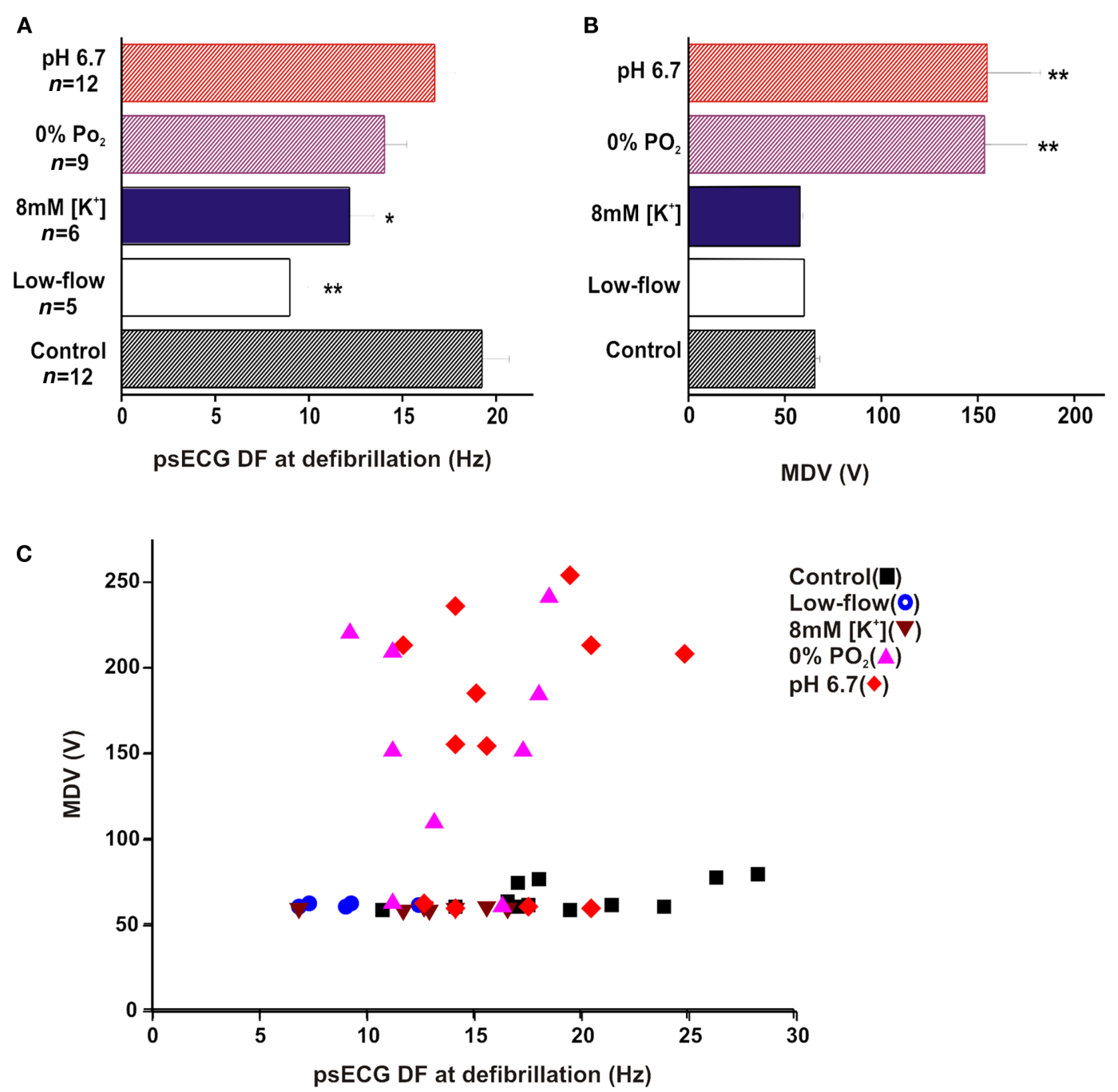

FIGURE 2 | Minimum defibrillation voltage and psECG DF. (A) Plot of mean psECG DF at point of defibrillation. The psECG DF was significantly lower than control during low-flow ischemia** and $8 \mathrm{mM}\left[\mathrm{K}^{+}\right]_{0}^{*}$. (B) Plot of mean MDV $\pm \mathrm{SE}$. The MDV was significantly raised by $\mathrm{pH} 6.7^{* *}$ and $0 \%$ $\mathrm{PO}_{2}{ }^{* *}$ when compared to control. (C) Scattergram of MDV against psECG
DF at defibrillation. Although there was a tendency for MDV to increase with DF in $0 \% \mathrm{PO}_{2}$ and $\mathrm{pH} 6.7$, there were no such associations in low-flow ischemia, $8 \mathrm{mM}\left[\mathrm{K}^{+}\right]_{\circ}$ or control. $\left({ }^{*} p<0.05,{ }^{* *} p<0.01\right)$. Considering all MDV vs $D F$, there was no significant correlation between the two parameters $(r=0.13)$. mechanisms of VF reinitiation have been proposed; from critical point re-entry (Wharton et al., 1992), through virtual electrodes (Efimov et al., 1998) to delayed after depolarizations (DADs; Chattipakorn and Ideker, 2003). Equally controversial is the effect of ischemia on DFT; the small number of studies examining the effect of global ischemia on DFT have shown conflicting results (Behrens et al., 1997; Barton et al., 2000). In the present study MDV was unaffected by low-flow ischemia (flow rate $=15 \%$ control), but small changes in DFT may have occurred below the minimum energy the current device could deliver. Despite this technical limitation, this result compares well to previous research in isolated rabbit hearts during global low-flow ischemia at $20 \%$ control flow rate (Behrens et al., 1997). Here Behrens et al. found no difference in the DFT during low-flow ischemia and control. In contrast, in isolated pig hearts, Barton et al. (2000) observed that the MDV was lowered in low-flow ischemia ( $10 \%$ standard rate) compared to control. Barton et al. (2000) hypothesized that the slower ECG DF in low-flow ischemia represented more organized myocardial electrical activity, which could be defibrillated more easily. Similarly, computer simulations have predicted the need for greater energies to convert increasingly complex electrical activity (Hillebrenner et al., 2004; Plank et al., 2005). Hillebrenner et al. (2004) showed in a bidomain defibrillation model that multiple scroll waves had a reduced probability of successful defibrillation compared to a single scroll wave in the same tissue. In a similar bidomain model Plank et al. (2005) produced increasingly complex electrical activity by adjusting the spatial modulations of $\mathrm{IK}_{\text {Ach. }}$ This transformed a single scroll wave into complex fibrillating activity. They showed that with increasing complexity of fibrillation higher shock strengths were required to successfully terminate the arrhythmia. 


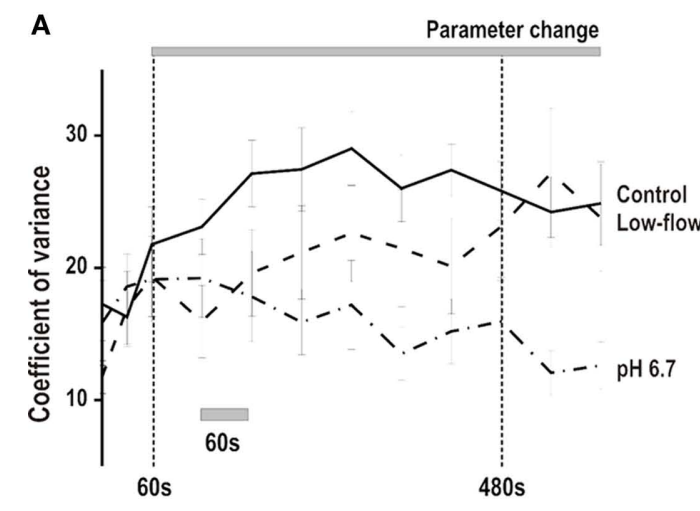

FIGURE 3 | Coefficient of variance of optical DF. (A) Time course of coefficient of variance during VF in low-flow ischemia, $\mathrm{pH} 6.7$ and control conditions. There was a tendency for the coefficient to increase with time in low-flow ischemia and control. In comparison, the coefficient tended to

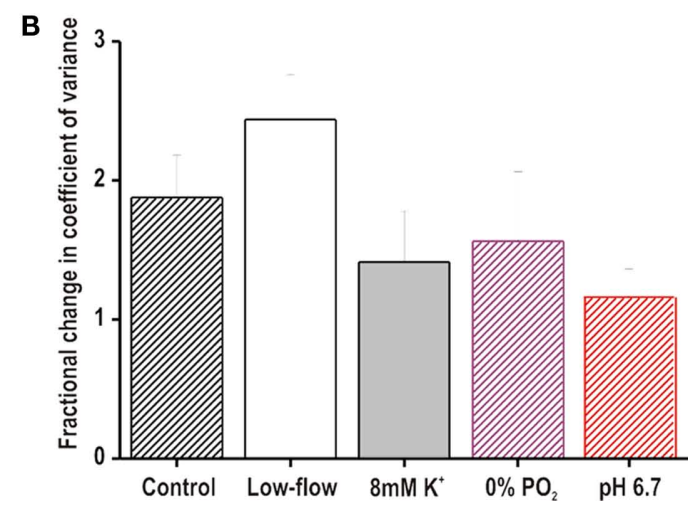

remain stable in $\mathrm{pH}$ 6.7. (B) Fractional change in the coefficient of variance at time of defibrillation compared to baseline values at VF onset. The fractional change was not significantly different between the experimental groups.

\section{IN RAISED $\left[\mathrm{K}^{+}\right]_{0}$}

Although no significant change in MDV was demonstrated in $8 \mathrm{mM}\left[\mathrm{K}^{+}\right]$solution, higher $\left[\mathrm{K}^{+}\right]$solutions resulted in spontaneous defibrillation. This suggests that the MDV may have been reduced in $8 \mathrm{mM}\left[\mathrm{K}^{+}\right]_{\mathrm{o}}$, but this change could not be resolved by the current experimental arrangement. As shown in Table 1, the Ventak ECD 2815 can only deliver biphasic shocks $>60 \mathrm{~V}$, and so MDV less than $\sim 60 \mathrm{~V}$ cannot be detected. As MDV of VF during control was $65.6 \pm 2.3 \mathrm{~V}$, a significant reduction of MDV was impossible to detect. Previous research supports this suggestion as DFT has been shown to be lowered by raised $\left[\mathrm{K}^{+}\right]_{\mathrm{o}}$ (Babbs et al., 1980). Here, cardiac perfusion was maintained by cardiopulmonary bypass, and arterial $\left[\mathrm{K}^{+}\right]_{\mathrm{o}}$ raised by potassium chloride infusion. Babbs et al. (1980) demonstrated that the percentage reduction of DFT was linearly related to $\log \left[\mathrm{K}^{+}\right]_{\mathrm{o}}$, and to the potassium equilibrium potential $\left(E_{\mathrm{K}}\right)$. This linear relationship suggests that $\left[\mathrm{K}^{+}\right]_{\mathrm{o}}$ reduces DFT by bringing the diastolic membrane potential closer to the cellular firing threshold of $-55 \pm 5 \mathrm{mV}$. Indeed, when the diastolic membrane potential was raised to $-46 \mathrm{mV}$ by $16 \mathrm{mM}\left[\mathrm{K}^{+}\right]_{0}$, spontaneous defibrillation occurred (Babbs et al., 1980).

The direct relationship between $\left[\mathrm{K}^{+}\right]_{\mathrm{o}}$ and DFT only applies to global increases in $\left[\mathrm{K}^{+}\right]_{0}$. Regional increases in $\left[\mathrm{K}^{+}\right]_{\mathrm{o}}$ increase the DFT (Sims et al., 2000). This was hypothesized to arise from the increased heterogeneity of various electrophysiology parameters such as repolarization, refractoriness, and conduction velocity.

\section{IN ACIDIC $\mathrm{pH}_{0}$}

In this study acidic $\mathrm{pH}_{\mathrm{o}}$ significantly increased the MDV compared to control. Once again previous research into the effects of acidic $\mathrm{pH}_{\mathrm{o}}$ on defibrillation is limited and conflicting. Kerber et al. (1983) showed no change in DFT with respiratory or metabolic acidosis, but the arterial $\mathrm{pH}$ was only reduced to 7.25. In contrast, another group demonstrated the need for more countershocks, with greater total defibrillation energy in hypercarbic acidosis with arterial $\mathrm{pH}$ 6.7 (Maldonado et al., 1993).

Acidic $\mathrm{pH}$ is well recognized for its arrhythmogenicity, being able to precipitate arrhythmias through four possible mechanisms: (i) triggered activity of EADs (Coraboeuf et al., 1980) and DADs
(Coetzee and Opie, 1987), (ii) producing a re-entrant substrate such as calcium alternans (Orchard et al., 1991), (iii) conduction slowing (Kagiyama et al., 1982), and (iv) increased gap junction resistance (Eloff et al., 2003). All of these mechanisms have been associated with defibrillation failure (Chattipakorn and Ideker, 2003; Chattipakorn et al., 2004).

\section{IN HYPOXIA}

In VF during hypoxia, the MDV was significantly increased. To date, only a few studies have investigated the effect of hypoxia on DFT. Of these studies, one canine study demonstrated that hypoxia lowered DFT (Kerber et al., 1983), whereas another showed the DFT to be unchanged (Yakaitis et al., 1975). Both studies used in situ hearts with CPR during VF. In such preparations the hypoxia-induced $\mathrm{K}^{+}$ efflux may be significant, thereby depolarizing the diastolic membrane potential, and thus lower the DFT (Babbs et al., 1980). In Langendorff-perfused rabbit hearts, the hypoxia-induced $\mathrm{K}^{+}$efflux cannot accumulate. In contrast hypoxia results in severe metabolic acidosis secondary to the accumulation of lactic acid (Bright and Ellis, 1992). Thus the electrophysiological adaptations that could contribute to MDV elevation in acidic $\mathrm{pH}_{\mathrm{o}}$ could also explain the increase MDV in hypoxia.

\section{LACK OF RELATIONSHIP BETWEEN DF AND MDV}

As discussed above, previous isolated heart studies have suggested a correlation between the complexity of the electrical activity and the required defibrillation energy (Barton et al., 2000; Hillebrenner et al., 2004; Rodriguez et al., 2004). In contrast, the slower electrical activity in clinical and in situ heart animal studies are associated with less successful defibrillation (Brown et al., 1989; Stewart et al., 1992), and partial restoration of perfusion increases the ECG DF (Berg et al., 2004; Eftestol et al., 2004), and improves defibrillation success (Niemann et al., 2000; Wik et al., 2003).

In this study, there was no correlation between the VF electrical activity as measured by the psECG DF immediately prior to defibrillation and the MDV. This lack of correlation is not surprising as the outcome of defibrillation is influenced by more than the electrical co-ordination at the point of defibrillation. Factors such 
as heterogeneity of refractoriness, conductivity (Kagiyama et al., 1982), and DAD (Chattipakorn and Ideker, 2003) all have roles to play in defibrillation failure.

\section{MECHANISTIC INSIGHTS INTO INCREASED MDV}

To date several theories exist as to why VF is reinitiated after defibrillation. This study highlights how no single electrophysiological mechanism is responsible in all cases of failed defibrillation.

\section{Dispersion of repolarization and refractoriness}

A key concept in defibrillation is heterogeneity of repolarization and refractoriness at defibrillation. Computer simulations predict that such increased electrical complexity will increase DFT by increased complexity of virtual electrode polarizations and therefore increasing the likelihood of formation of point singularities to re-establish VF (Plank et al., 2005). Previous studies have used the $\mathrm{CoV}$ of the VFI to assess the dispersion of refractoriness (Opthof et al., 1991, 1993; Burton and Cobbe, 1998; Burton et al., 2000). In this study, the $\mathrm{CoV}$ of DF was calculated. This failed to show any significant change in electrical heterogeneity either between, or within protocols. This suggests that increased dispersion of heterogeneity of refractoriness is not a pre-requisite to increased defibrillation energy.

Coefficient of variance of DF does not examine the influence of alteration of repolarization. However this is also unlikely to be a pre-requisite for defibrillation failure as in this study both hypoxia and acidic $\mathrm{pH}_{\mathrm{o}}$ were responsible for increasing MDE. Previous studies show that hypoxia results in early shortening of repolarization (Kodama et al., 1984; Tissier et al., 2002), whereas acidic $\mathrm{pH}_{\mathrm{o}}$ is more likely to cause APD prolongation (Spitzer and Hogan, 1979; Kagiyama et al., 1982). However, action potential duration does not necessarily correlate with DF because changes in post-repolarization refractoriness do not always follow action potential duration. Previous studies by Caldwell et al. (2007) show a shortening of action potential duration during perfusion with raise extracellular potassium, but no change in effective refractory period.

\section{Alteration in conduction velocity}

Alterations in conductivity have also been implicated in defibrillation failure by increasing the likelihood of point singularity formation (Plank et al., 2005). Although not examined in this study

\section{REFERENCES}

Anastasiou-Nana, M. I., Tsagalou, E. P., Charitos, C., Siafakas, K. X., Drakos, S., Terrovitis, J. V., Ntalianis, A., Doufas, A., Mavrikakis, J., and Nanas, J. N. (2005). Effects of transient myocardial ischemia on the ventricular defibrillation. Pacing. Clin. Electrophysiol. 28, 97-101.

Atwood, C., Eisenberg, M. S., Herlitz, J., and Rea, T. D. (2005). Incidence of EMS-tsreated out-of-hospital cardiac arrest in Europe. Resuscitation 67, 75-80.

Babbs, C. F., Whistler, S. J., Yim, G. K., Tacker, W.A., and Geddes, L.A. (1980).

alterations in conductivity are again unlikely to be the unifying mechanism of increased MDE. Whilst hypoxia has minimal effect on conductivity (Veenstra et al., 1987), acidic pH has a profound slowing effect (Kagiyama et al., 1982; Veenstra et al., 1987).

\section{$D A D$ generation}

A final mechanism of defibrillation failure suggested by Chattipakorn and Ideker (2003) is the reinitiation of VF by DADs. This hypothesis was suggested after the DAD inhibitor, flunarizine, was shown to significantly improve defibrillation efficacy. This is unlikely to be a unifying mechanism to the varied MDEs observed in this study. Whilst acidic $\mathrm{pH}_{\mathrm{o}}$ has been shown to increase the likelihood of DADs, hypoxia has been documented to decrease their incidence (Coetzee and Opie, 1987).

\section{SUMMARY}

In summary, conditions that reduced the overall frequency of VF (i.e., low-flow ischemia or raised extracellular $\left[\mathrm{K}^{+}\right]_{\mathrm{o}}$ ) did not increase the defibrillation energy to the same extent as that induced by acidic and hypoxic conditions. Neither of these latter conditions significantly affected the frequency of VF. This is the first study to report two ischemic conditions (acidic $\mathrm{pH}$ and hypoxia) that substantially increase MDV without changing the DF of VF. The study also shows a lack of association between dispersion of refractoriness and defibrillation energies, suggesting that increased heterogeneity of refractoriness is not a pre-requisite for reduced defibrillation success.

\section{CLINICAL RELEVANCE}

This study demonstrated that during prolonged VF the MDV was increased by hypoxia and acidic $\mathrm{pH}_{\mathrm{o}}$. The reversal of acidosis with buffering agent has previously been attempted with varying success (Kette et al., 1990; Bar-Joseph et al., 1998). This probably relates to the fact that in ischemia the acidosis is primarily an intracellular lactic acidosis, which buffers are less able to reverse (Kette et al., 1990). Establishing perfusion and maximizing oxygenation are more likely to reverse this acidosis (Idris et al., 1994).

\section{ACKNOWLEDGMENT}

Dr. Jane C. Caldwell was supported during this work through the British Heart Foundation Clinical PhD Fellowship scheme.

energy in isolated fibrillating hearts. Pacing. Clin. Electrophysiol. 23, 504-511.

Behrens, S., Li, C., and Franz, M. R. (1997). Effects of myocardial ischemia on ventricular fibrillation inducibility and defibrillation efficacy. J. Am. Coll. Cardiol. 29, 817-824.

Berg, R. A., Hilwig, R. W., Ewy, G. A., and Kern, K. B. (2004). Precountershock cardiopulmonary resuscitation improves initial response to defibrillation from prolonged ventricular fibrillation: a randomized, controlled swine study. Crit. Care Med. 32, 1352-1357.
Bethell, H. W., Vandenberg, J. I., Smith, G. A., and Grace, A. A. (1998). Changes in ventricular repolarization during acidosis and low-flow ischemia. Am. J. Physiol. Heart Circ. Physiol. 275, H551-H561.

Bright, C. M., and Ellis, D. (1992). Intracellular $\mathrm{pH}$ changes induced by hypoxia and anoxia in isolated sheep heart Purkinje fibres. Exp. Physiol. 77, 165-175.

Brown, C. G., Dzwonczyk, R., Werman, H. A., and Hamlin, R. L. (1989). Estimating the duration of ventricular fibrillation. Ann. Emerg. Med. 18, 1181-1185. 
Burton, F. L., and Cobbe, S. M. (1998). Effect of sustained stretch on dispersion of ventricular fibrillation intervals in normal rabbit hearts. Cardiovasc. Res. 39, 351-359.

Burton, F. L., McPhaden, A. R., and Cobbe, S. M. (2000). Ventricular fibrillation threshold and local dispersion of refractoriness in isolated rabbit hearts with left ventricular dysfunction. Basic Res. Cardiol. 95, 359-367.

Caldwell, J. C., Burton, F. L., Smith, G. L., and Cobbe, S.M. (2007). Heterogeneity of ventricular fibrillation dominant frequency during global ischemia in isolated rabbit hearts. J. Cardiovasc. Electrophysiol. 18, 854-861.

Carlisle, E. J., Allen, J. D., Kernohan, W. G., Anderson, J., and Adgey, A. A. (1990). Fourier analysis of ventricular fibrillation of varied aetiology. Eur. Heart J. 11, 173-181.

Chattipakorn, N., Banville, I., Gray, R. A., and Ideker, R.E. (2004). Effects of shock strengths on ventricular defibrillation failure. Cardiovasc. Res. 61, 39-44.

Chattipakorn, N., and Ideker, R. E. (2003). Delayed afterdepolarization inhibitor: a potential pharmacologic intervention to improve defibrillation efficacy. J. Cardiovasc. Electrophysiol. 14, 72-75.

Chen, J., Mandapati, R., Berenfeld, O., Skanes, A.C., and Jalife, J. (2000). Highfrequency periodic sources underlie ventricular fibrillation in the isolated rabbit heart. Circ. Res. 86, 86-93.

Choi, B. R., Hatton, W. J., Hume, J. R., Liu, T., and Salama, G. (2006). Low osmolarity transforms ventricular fibrillation from complex to highly organized, with a dominant high-frequency source. Heart Rhythm 3, 1210-1220.

Coetzee, W. A., and Opie, L. H. (1987). Effects of components of ischemia and metabolic inhibition on delayed afterdepolarizations in guinea pig papillary muscle. Circ. Res. 61, 157-165.

Coraboeuf, E., Deroubaix, E., and Coulombe, A. (1980). Acidosisinduced abnormal repolarization and repetitive activity in isolated dog Purkinje fibers. J. Physiol. (Paris) 76, 97-106.

Efimov, I. R., Cheng, Y., Van Wagoner, D. R., Mazgalev, T., and Tchou, P. J. (1998). Virtual electrode-induced phase singularity: a basic mechanism of defibrillation failure. Circ. Res. 82, 918-925.

Eftestol, T., Wik, L., Sunde, K., and Steen, P. A. (2004). Effects of cardiopulmonary resuscitation on predictors of ventricular fibrillation defibrillation success during out-of-hospital cardiac arrest. Circulation 110, 10-15.

Eloff, B. C., Gilat, E., Wan, X., and Rosenbaum, D. S. (2003).
Pharmacological modulation of cardiac gap junctions to enhance cardiac conduction: evidence supporting a novel target for antiarrhythmic therapy. Circulation 108, 3157-3163.

Hillebrenner, M. G., Eason, J. C., and Trayanova, N. A. (2004). Mechanistic inquiry into decrease in probability of defibrillation success with increase in complexity of preshock reentrant activity. Am. J. Physiol. Heart Circ. Physiol. 286, H909-H917.

Ideker, R. E., Huang, J., and Walcott, G. P. (2006). "Defibrillation waveforms," in Cardiac Electrophysiology From cell to bedside, eds D. P. Zipes and J. Jalife (Philadelphia: Saunders), 426-432.

Idris, A. H., Staples, E. D., O’Brien, D. J., Melker, R. J., Rush, W. J., Del Duca, K. D., and Falk, J. L. (1994). Effect of ventilation on acid-base balance and oxygenation in low blood-flow states. Crit. Care Med. 22, 1827-1834.

Jennings, R. B., Murry, C. E., Steenbergen, C., and Reimer, K. A. (1990). Development of cell injury in sustained acute ischemia. Circulation 82, II-2-II-12.

Kagiyama, Y., Hill, J. L., and Gettes, L. S. (1982). Interaction of acidosis and increased extracellular potassium on action potential characteristics and conduction in guinea pig ventricular muscle. Circ. Res. 51, 614-623.

Kerber, R. E., Pandian, N. G., Hoyt, R., Jensen, S. R., Koyanagi, S., Grayzel, J., and Kieso, R. (1983). Effect of ischemia, hypertrophy, hypoxia, acidosis, and alkalosis on canine defibrillation. Am. J. Physiol. 244, H825-H831.

Kette, F., Weil, M. H., von Planta, M., Gazmuri, R. J., and Rackow, E. C. (1990). Buffer agents do not reverse intramyocardial acidosis during cardiac resuscitation. Circulation 81, 1660-1666.

Kettlewell, S., Walker, N. L., Cobbe, S. M., Burton, F. L., and Smith, G. L. (2004). The electrophysiological and mechanical effects of 2,3-butanedione monoxime and cytochalasin$\mathrm{D}$ in the Langendorff perfused rabbit heart. Exp. Physiol. 89, 163-172.

Kleber, A. G. (1983). Resting membrane potential, extracellular potassium activity, and intracellular sodium activity during acute global ischemia in isolated perfused guinea pig hearts. Circ. Res. 52, 442-450.

Kodama, I., Wilde, A., Janse, M. J., Durrer, D., and Yamada, K. (1984). Combined effects of hypoxia, hyperkalemia and acidosis on membrane action potential and excitability of guinea-pig ventricular muscle. J. Mol. Cell. Cardiol. 16, 247-259.

Maldonado, F. A., Weil, M. H., Tang, W., Bisera, J., Gazmuri, R. J., Johnson, B., and D'Alessio, A. (1993). Myocardial hypercarbic acidosis reduces cardiac resuscitability. Anesthesiology 78 343-352.

Natale, A., Sra, J., Krum, D., Dhala, A., Deshpande, S., Jazayeri, M., Newby, K., Wase, A., Axtell, K., VanHout, W. L., and Akhtar, M. (1996). Relative efficacy of different tilts with biphasic defibrillation in humans. Pacing. Clin. Electrophysiol. 19, 197-206.

Niemann, J. T., Cruz, B., Garner, D., and Lewis, R. J. (2000). Immediate countershock versus cardiopulmonary resuscitation before countershock in a 5-minute swine model of ventricular fibrillation arrest. Ann. Emerg. Med. 36, 543-546.

Opthof, T., Coronel, R., Vermeulen, J. T., Verberne, H. J., van Capelle, F. J., and Janse, M. J. (1993). Dispersion of refractoriness in normal and ischaemic canine ventricle: effects of sympathetic stimulation. Cardiovasc. Res. 27, 1954-1960.

Opthof, T., Misier, A. R., Coronel, R., Vermeulen, J. T., Verberne, H. J., Frank, R. G., Moulijn, A. C., van Capelle, F. J., and Janse, M. J. (1991). Dispersion of refractoriness in canine ventricular myocardium. Effects of sympathetic stimulation. Circ. Res. 68, 1204-1215.

Orchard, C. H., McCall, E., Kirby, M. S. and Boyett, M. R. (1991). Mechanical alternans during acidosis in ferret heart muscle. Circ. Res. 68, 69-76.

Ouyang, P., Brinker, J. A., Bulkley, B. H., Jugdutt, B. I., and Varghese, P.J. (1981). Ischemic ventricular fibrillation: the importance of being spontaneous. Am. J. Cardiol. 48, 455-459.

Plank, G., Leon, L. J., Kimber, S., and Vigmond, E. J. (2005). Defibrillation depends on conductivity fluctuations and the degree of disorganization in reentry patterns. J. Cardiovasc. Electrophysiol. 16, 205-216.

Qin, H., Walcott, G. P., Killingsworth, C. R., Rollins, D. L., Smith, W. M., and Ideker, R. E. (2002). Impact of myocardial ischemia and reperfusion on ventricular defibrillation patterns, energy requirements, and detection of recovery. Circulation 105, 2537-2542.

Rodriguez, B., Tice, B., Blake, R. Gavaghan, D., and Trayanova, N. (2006).Vulnerability to electric shocks in the regionally-ischemic ventricles. Conf. Proc. IEEE Eng. Med. Biol. Soc. 1, 2280-2283.

Rodriguez, B., Tice, B. M., Eason, J. C., Aguel, F., Ferrero, J. M. Jr., and Trayanova, N. (2004). Effect of acute global ischemia on the upper limit of vulnerability: a simulation study. Am. J. Physiol. Heart Circ. Physiol. 268, 2078-2088.
Rubart, M., and Zipes, D. (2005). “Genesis of cardiac arrhythmias: electrophysiological considerations," in Heart Disease: A Textbook of Cardiovascular Medicine, eds E. Braunwald, D.Zipes, and P. Libby (Philadelphia:W.B.Saunders), 803-861.

Samie, F. H., Berenfeld, O., Anumonwo, J., Mironov, S. F., Udassi, S., Beaumont J., Taffet, S., Pertsov, A. M., and Jalife, J. (2001). Rectification of the background potassium current: a determinant of rotor dynamics in ventricular fibrillation. Circ. Res. 89, 1216-1223.

Sims, J. J., Miller, A. W., and Ujhelyi, M. R. (2000). Regional hyperkalemia increases ventricular defibrillation energy requirements: role of electrical heterogeneity in defibrillation. $J$. Cardiovasc. Electrophysiol. 11,634-641.

Spitzer, K. W., and Hogan, P. M. (1979). The effects of acidosis and bicarbonate on action potential repolarization in canine cardiac Purkinje fibers. J. Gen. Physiol. 73, 199-218.

Stewart, A. J., Allen, J. D., and Adgey, A. A. (1992). Frequency analysis of ventricular fibrillation and resuscitation success. Q. J. Med. 85, 761-769.

Strohmenger, H. U., Lindner, K. H., and Brown, C. G. (1997). Analysis of the ventricular fibrillation ECG signal amplitude and frequency parameters as predictors of countershock success in humans. Chest 111, 584-589.

Tissier, C., Bes, S., Vandroux, D., Fantini, E., Rochette, L., and Athias, P. (2002). Specific electromechanical responses of cardiomyocytes to individual and combined components of ischemia. Can J. Physiol. Pharmacol. 80, 1145-1157.

Ujhelyi, M. R., Sims, J. J., and Miller, A. W. (1999). Induction of electrical heterogeneity impairs ventricular defibrillation: an effect specific to regional conduction velocity slowing. Circulation 100, 2534-2540.

Veenstra, R. D., Joyner, R. W., Wiedmann, R. T., Young, M. L., and Tan, R. C. (1987). Effects of hypoxia, hyperkalemia, and metabolic acidosis on canine subendocardial action potential conduction. Circ. Res. 60, 93-101.

Wharton, J. M., Wolf, P. D., Smith, W. M., Chen, P. S., Frazier, D. W., Yabe, S., Danieley, N., and Ideker, R. E. (1992). Cardiac potential and potential gradient fields generated by single, combined, and sequential shocks during ventricular defibrillation. Circulation 85, 1510-1523.

Wik, L., Hansen, T. B., Fylling, F., Steen, T., Vaagenes, P., Auestad, B. H., and Steen, P. A. (2003). Delaying defibrillation to give basic cardiopulmonary resuscitation to patients with out-of-hospital ventricular fibrillation: a randomized trial. JAMA 289, 1389-1395. 
Wu, T. J., Lin, S. F., Hsieh, Y. C., Ting, C. T., and Chen,P.S.(2006). Ventricular fibrillation during no-flow global ischemia in isolated rabbit hearts. J. Cardiovasc. Electrophysiol. 17, 1112-1120.

Yakaitis, R. W., Thomas, J. D., and Mahaffey, J.E. (1975). Influence of $\mathrm{pH}$ and hypoxia on the success of defibrillation. Crit. Care Med. 3, 139-142.
Conflict of Interest Statement: The authors declare that the research was conducted in the absence of any commercial or financial relationships that could be construed as a potential conflict of interest.

Received: 16 September 2010; accepted: 09 March 2011; published online: 06 April 2011.
Citation: Caldwell JC, Burton FL, Cobbe SM and Smith GL (2011) Slowing of electrical activity in ventricular fibrillation is not associated with increased defibrillation energies in the isolated rabbit heart. Front. Physio. 2:11. doi: 10.3389/fphys.2011.00011 This article was submitted to Frontiers in Cardiac Electrophysiology, a specialty of Frontiers in Physiology.
Copyright (c) 2011 Caldwell, Burton, Cobbe and Smith. This is an open-access article subject to a non-exclusive license between the authors and Frontiers Media $S A$, which permits use, distribution and reproduction in other forums, provided the original authors and source are credited and other Frontiers conditions are complied with. 